\title{
A COMPARATIVE STUDY OF COLOUR PREFERENCES TOWARDS CLOTHING AMONG YOUNG GIRLS AND BOYS
}

Dr. Ranjana Upadhayay

Assistant Professor, Home Science

HOD, Department of Fashion Designing, Institute for Excellence in Higher Education, Bhopal

Email: ranjanapratyush@gmail.com

\section{INTRODUCTION}

Colour, is the visual perceptual property corresponding in human beings to the names called red, green, blue, and so on and so forth. Colours are derived from the spectrum of light, interacting in the eye with the spectral sensitivities of the light receptors. Colour categories and physical specifications are related to objects or materials based on their physical properties such as light absorption, reflection, or emission.

The meanings of colors vary according to cultures and environments. Each color has many aspects which may be expressed as the language of color by understanding few concepts. Colour is a form of non-verbal communication. The perception of color stems from varying spectral sensitivity of different types of cone cells in the retina to different parts of the spectrum, and thus colors may be defined and quantified by the degree to which they stimulate these cells.

The science of color is called chromatics, colorimetry, or simply color science. It includes the perception of color by the human eye and brain, the origin of color in materials, color in art, and the physics of electromagnetic radiation in the visible range (that is, what we commonly refer to as light).

\section{Color in the Brain}

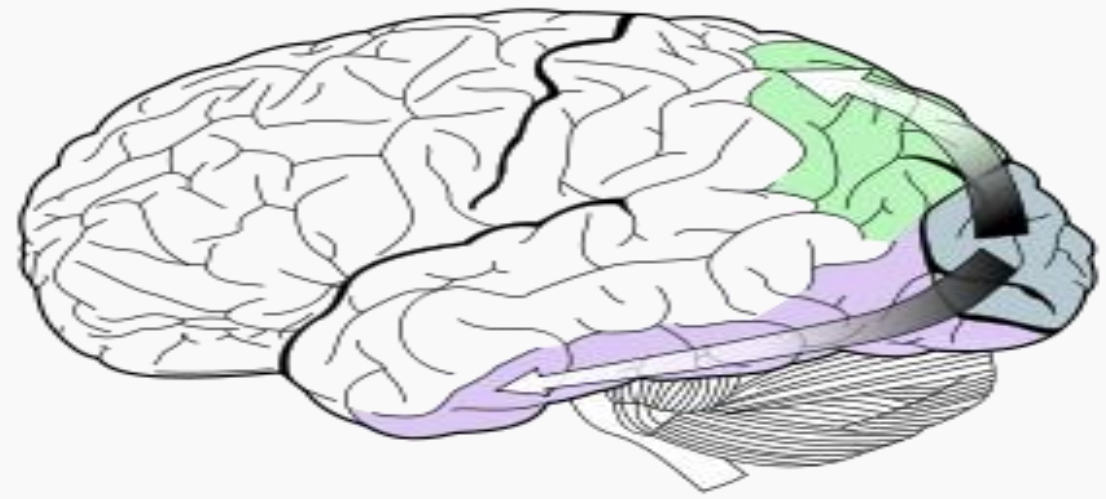

The visual dorsal stream (green) and ventral stream (purple) are shown. The ventral stream is responsible for color perception.

Keeping in view the vitality of colors in science and life, the present paper is aimed to identify the color preferences towards clothing among young girls and boys s. In order to fulfill the objective of the study, few basic terms are introduced and explained below. 


\section{CLOTHING}

\section{"Clothes make the man"}

The saying goes. The general assumption usually made is that clothes may be used to reflect, to express, or to enhance ones personality. Clothing as a part of body image acts as a "Second Skin" and establishing the physical boundaries of self. It is common to assume that the locus of the self is contained within the body and that the skin marks the distinction between the self and the environment. But in our society almost from the moment of birth on there is some form of clothing which separates the body from the surroundings. Clothes are now a part of body image. At every stage of development, clothing helps to establish the identity of the individual to himself and to those with whom he interacts. Clothing is a general reflection of how the individual thinks of himself. Although the accuracy of such judgment may be altered by faulty perception, lack of knowledge or the operation of defense mechanism. Clothing is a part of "silent language" that is communicated through the use of visual but non verbal symbols.

\section{ADOLOSCENCE}

Adolescence has been derived from Latin word adolescere meaning "to grow up". It is defined as a transitional stage of physical and mental human development generally occurring between puberty and legal adulthood (age of majority), but largely characterized as beginning and ending with the teenage stage. According to Erik Erikson's stages of human development, an adolescent is a person between the ages of 13 and 19. Adolescence is usually accompanied by an increased independence allowed by the parents or legal guardians and less supervision, contrary to the preadolescence stage. In many societies, adolescence was not recognized as a phase of life. Most societies simply distinguished between childhood and adulthood.

Along with physical and psychological changes, this period represents a change in lifestyle too, whether it is entering in college, choosing hairstyles etcetera. It's a phase that has new wardrobe demands. Both a high interest in personal appearance and assumption of new roles make these years the most costly in terms of clothing expenditure.

\section{PERSONALITY}

Personality is the mirror of ourselves our own fashion style a fashion statement is rely on our taste in every fashion apparel (Ralph Lawren, 2007). If someone has a good taste on fashion or in studying or in styling it implies that the person possesses a strong personality as well. Personality is the particular combination of emotional, attitudinal, and behavioral response patterns of an individual.

\section{COLOURS AND PERSONALITY}

The choice of colors tells a lot about oneself, how one function and how others perceive the person. It is the means to understanding one's behavior and character traits as well as one's physical, mental, emotional and spiritual states. It reflects the way people operate in the world, their strengths and weaknesses, their vulnerabilities, their needs and challenges in life. 


\section{INTERNATIONAL JOURNAL of RESEARCH -GRANTHAALAYAH \\ A knowledge Repository}

Art

The psychology of color is based on the mental and emotional effects colors have on sighted people in all facets of life. In art therapy, color is often associated with a person's emotions. Color may also influence a person's mental or physical state.

\section{STUDIES ON COLOURS AND PERSONALITY}

Charlene Lind in her paper titled Psychology of Color: Similarities between Clothing, Color and Preferences, published in Clothing and Textiles Research Journal January 1, 2001, Vol. 19: pp. 64-75 conducted two studies, one of university students and one of non-students, of the similarities between color preferences as an abstract concept and color preferences for clothing are reported. Using Munsell color standards in a controlled viewing setting, subjects ranked preferences for 10 hues, the color of a favorite garment, and dominant colors in their wardrobe. Results of the study show that blue and purple-blue were most preferred hues for any use. Colours of favorite garments and dominant colors in the wardrobe were similar to stated color preferences. Findings support the importance of both biological and social factors influence on color preferences. Knowledge of color preferences is useful for planning colors of consumer products, but color preferences may be product specific. The $15 \%$ to $25 \%$ of subjects who selected different colors as most preferred for abstract color and clothing color present an obstacle to using clothing colors as indicators of personality traits.

Further, Judy Williams, Joyce Arbaugh, and Margaret Rucker in their article titled Clothing Colour Preferences of Adolescent Females, published in the Family and Consumer Sciences Journal Volume 9, Issue 1, pp. 57-63, September 2009 studied Sixty black and sixty white female high school students who were asked to indicate their hue; hue, tint, or shade; and color combination choices for clothing. To standardize measurement conditions for each of these 3selection situations, subjects were provided with color cards and transparent overlays of a fashion figure. Chi-square analyses indicated that the two groups were generally similar in their preferences except for hue, tint, or shade choices. When asked to select from among pure hues and corresponding Chroma, the majority of the black subjects showed a preference for pure hues whereas white subjects favored tints. For both groups, shades were the least often preferred.

\section{OBJECTIVE}

The objective of the present study is to examine the color preferences towards clothing among young girls and boys.

\section{HYPOTHESIS}

$\mathrm{H}_{1}$ there will be a significant difference between the color preferences towards clothing among young girls and boys.

$\mathrm{H}_{2 \mathrm{i}}$ An introvert personality type will prefer simple design light colored dresses.

$\mathrm{H}_{2 \mathrm{ii}}$ An extrovert personality type will prefer colorful attractive outfits.

\section{METHOD}




\section{INTERNATIONAL JOURNAL of RESEARCH -GRANTHAALAYAH \\ A knowledge Repository}

Art

\section{PARTICIPANTS}

The study sample comprises of students from various colleges of Bhopal city. Factors affecting mode of clothing of all respondents were measured with the help of standardized and self developed scale. After the collecting of data and applying appropriate statistical analysis for its meaningful presentation and interpretation the results of the studies are presented in the following sections. The total strength of the sample constituted of $\mathrm{N}=200$ students, of which $\mathrm{n}_{1}=100$ were girls and $\mathrm{n}_{2}=100$ were boys. In the processing of the sample, the age range of the respondents was from 18 to 23 years.

\section{RESULTS}

Table 1: Showing comparison of responses of girls and boys on Texture

\begin{tabular}{|c|l|l|l|}
\hline \multirow{2}{*}{ Texture } & \multicolumn{2}{|l|}{ Mean } & t-value \\
\cline { 2 - 3 } (Equal Variance assumed) & Girls & Boys & -4.30 \\
\cline { 2 - 3 } & 1.37 & 1.63 & \\
\hline
\end{tabular}

The $\mathrm{t}$-test table indicates that the $\mathrm{t}$-value for texture $(\mathrm{t}=-4.307, \mathrm{p}<.01)$ was obtained significant. The mean value for girls $(\mathrm{G}=1.13701)$ and boys $(\mathrm{B}=1.1638)$. It indicates that brighter texture was preferred more by girls as compared to boys.

Table 2: Showing comparison of responses of girls and boys on Colour

\begin{tabular}{|c|l|l|l|}
\hline \multirow{2}{*}{ Texture } & \multicolumn{2}{|l|}{ Mean } & t-value \\
\cline { 2 - 3 } (Equal Variance assumed & Girls & Boys & -4.04 \\
\cline { 2 - 3 } & 1.24 & 1.07 & \\
\hline
\end{tabular}

The $\mathrm{t}$-test table indicates that the $\mathrm{t}$-value for colour $(\mathrm{t}=-4.045, \mathrm{p}<.01)$ was obtained significant. The mean value for girls $(\mathrm{G}=1.2403)$ was higher than that for boys $(\mathrm{B}=1.0791)$. It indicates that bright color clothing was preferred more by girls as compared to boys.

Table 3: Showing Correlation of Part A of the self made tool with Extraversion (A dimension of personality)

\begin{tabular}{|l|c|}
\hline Variable & Coefficient of correlation \\
\hline Extraversion & $\mathrm{r}=0.002$ \\
\hline Colour & \\
\hline
\end{tabular}

The color (bright) was not obtained correlated with extraversion $(\mathrm{r}=0.002)$. It indicated that the color of clothes that college going students wear have no connection with them being extrovert otherwise. 
Table 4: Showing Correlation of Part A of the self made tool with Extraversion (A dimension of personality)

\begin{tabular}{|l|c|}
\hline Variable & Coefficient of correlation \\
\cline { 1 - 1 } Extraversion & $r=0.045$ \\
\cline { 1 - 1 } Aim & \\
\hline
\end{tabular}

The aim of clothing was not obtained correlated with extraversion $(r=0.045)$. It indicated that the aim of clothing that college going students wear have no relation with them being extrovert otherwise.

Graph showing correlation of variables with Modernity-

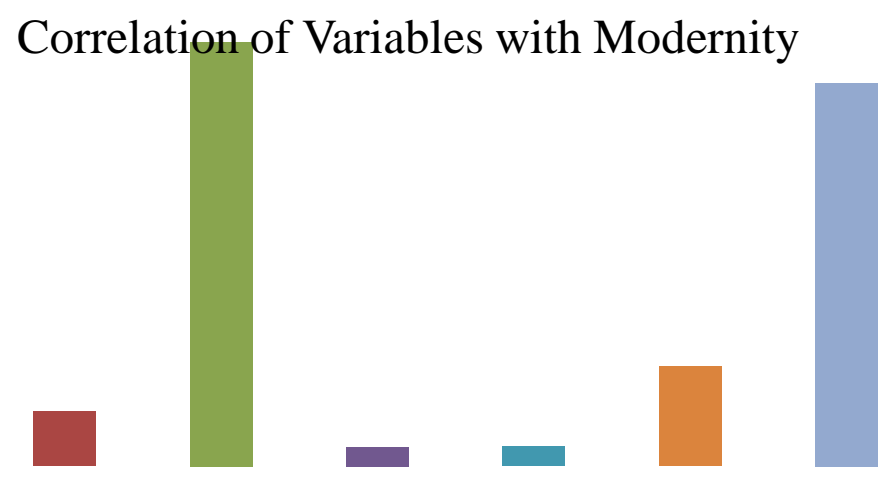

\section{CONCLUSIONS}

The investigator concluded thus that the brighter texture was preferred more by girls as compared to boys. Further bright colored clothing was preferred more by girls as compared to boys. The dressing style of the college going student would be in accordance to their personalities which means to say that an introvert personality type will prefer simple design and light colored dresses where as an extrovert personality type will prefer colorful and attractive outfits. 